\section{CORPO, TECNOLOGIA E DESPORTO: CONSIDERAÇÕES A PARTIR DO CASO DA PARATLETA DANIELLE BRADSHAW}

\author{
BODY, TECHNOLOGY AND SPORT: CONSIDERATIONS ON PARA-ATHLETE \\ DANIELLE BRADSHAW'S CASE
}

CUERPO, TECNOLOGÍA Y DEPORTE: CONSIDERACIONES A PARTIR DEL CASO DE LA PARATLETA DANIELLE BRADSHAW

Fabio Zoboli*, Elder Silva Correia**, Adolfo Ramos Lamar***

\section{Palavras-chave} Corpo humano. Esportes. Axiologia. Ontologia. Traumatismos em atletas.

\section{Keywords} Human Body. Sports. Axiology. Ontology. Athletes' injuries.

\section{Palabras clave} Cuerpo humano. Deportes.

Axiología. Ontología. Traumatismos en atletas.

\begin{abstract}
Resumo: Amputada da perna direita em 2010, a adolescente britânica Danielle Bradshaw começa a fazer atletismo paradesportivo. Devido aos excessivos treinamentos, a outra perna da paratleta ficou sobrecarregada, causando várias lesões que fizeram cair seu rendimento. Dessa forma, Danielle vê na amputação de sua perna esquerda uma alternativa na busca da realização de seu sonho: competir uma paralimpíada. O presente ensaio pretende discutir a problemática do uso da tecnologia no âmbito esportivo e os desdobramentos desta no que tange a debates de cunho ontológico e axiológico.
\end{abstract}

\begin{abstract}
After having her right leg amputated in 2010, British adolescent Danielle Bradshaw began to practice parasport athletics. Due to excessive training, her left leg was overloaded, which caused several injuries that reduced her performance. Therefore, Bradshaw saw the amputation of her left leg as a way for her dream of competing in a Paralympics to come true: This paper discusses the problem of using technology in sports and its ramifications in ontological and axiological debates.
\end{abstract}

Resumen: En 2010, cuando le amputaron la pierna derecha, la adolescente británica Danielle Bradshaw comienza a practicar atletismo paradeportivo. Debido a los excesivos entrenamientos, la otra pierna de la paratleta resultó sobrecargada, provocando varias lesiones que hicieron caer su rendimiento. De esta forma, Danielle ve en la amputación de su pierna izquierda una alternativa en su búsqueda de la realización de su sueño: competir en una paraolimpíada. El presente ensayo pretende discutir la problemática del uso de la tecnología en al ámbito deportivo y sus desdoblamientos en debates de cuño ontológico y axiológico. El hilo conductor de la reflexión del ensayo será el caso de la paratleta británica Danielle Bradshaw.
*Universidade Federal de Sergipe (UFS). Aracaju, SE, Brasil. E-mail: zobolito@gmail.com

** Universidade Federal do Espírito Santo (UFES). Vitória, ES, Brasil. E-mail: eldercorreia21@gmail.com

*** Fundação Universidade Regional de Blumenau (FURB). Blumenau, SC, Brasil. E-mail: ajemabra@yahoo.com.br

Recebido em: 15-06-2015 Aprovado em: 06-01-2016 (c) (1) (8) Licence 


\section{INTRODUÇÃO}

Uma das principais características (ou, talvez, a principal) da contemporaneidade é a incorporação de tecnologias nas mais variadas facetas de nossas vidas, nos mais diversos níveis e graus. $O$ uso de tecnologias tornou-se recorrente, sendo um forte meio de relação entre nós, humanos, com o mundo. Nesse sentido, os aparatos tecnológicos não só vêm transformando o nosso cotidiano, mas, também, a nós mesmos naquilo que talvez (ainda?) tenhamos de mais "natural": nosso corpo.

"Do lado do organismo: seres humanos que se tornam, em variados graus, 'artificiais'. Do lado da máquina: seres artificiais que não apenas simulam características dos humanos, mas que se apresentam melhorados relativamente a esses últimos" (SILVA, 2009, p.11). Esse pensamento é compactuado por Triviño (2012), quando menciona que na contemporaneidade o ser humano vem experimentando transformações profundas no que tange à sua fusão com a tecnologia. Segundo o autor, a genética, a robótica, a biomedicina, a nanotecnologia (dentre outras) estão oportunizando ao humano um hibridismo com a tecnologia na medida em que são ordenados outros componentes dentro do próprio organismo.

O desporto e o paradesporto, ambos como fenômenos sociais não ficam imunes a estas questões das tecnologias e são atravessados abruptamente por elas, como bem nos descreve Triviño (2012, p. 5),

En cualquier caso, el deporte no está al margen de los avances tecnológicos mejoradores de las capacidades fisiológicas; no quedará inmune a estos futuros cambios engendrados por la tecnología, por muy vagos e inconcretos que nos puedan parecer en el presente, sino que además muy probablemente será una de las esferas sociales en las que esas transformaciones sobre el cuerpo humano serán experimentadas por primera vez.

A incorporação de tecnologias presente no meio esportivo vem cada vez mais recebendo importância no desenvolvimento dos atletas que visam a um avanço técnico ou físico para melhorar suas performances rumo à superação de limites e quebra de recordes. Exemplo disso é o polêmico caso da paratleta britânica Danielle Bradshaw, que, amputada de uma das pernas, tornou-se conhecida no âmbito mundial ao declarar que quer cortar a segunda perna e, em seu lugar, colocar outra prótese de fibras de carbono. Amputada aos 11 anos, ela agora quer retirar a outra perna pois, segundo ela, a perna natural Ihe impossibilita uma melhor performance atlética devido às sequentes lesões causadas pelo excesso de treinamento. Com duas pernas artificiais, Danielle acredita poder melhorar suas marcas e, assim, realizar o seu sonho de participar de uma paralimpíada, podendo competir em alto nível ${ }^{1}$. A escolha do caso da paratleta Danielle Bradshaw para guiar as discussões que fizemos neste texto é significativa, pois permite discussões acerca de questões ontológicas e axiológicas que causam litígios ao cenário esportivo na contemporaneidade.

1 A reportagem publicada em 6 de outubro de 2014 no site alemão "Spiegel on-line: Schulspiegel" intitulada: Estudante planeja amputação "Sem minha perna eu posso correr mais rápido" deixa claro o desejo manifestado por Danielle: "O desejo de Danielle Bradshaw é tão radical como excepcional. A estudante de 15 anos de idade, de Manchester, quer amputar a segunda perna para cumprir seu sonho de ir aos jogos Paralímpicos de 2016 no Rio de Janeiro. 'Para o futuro, espero ter amputado as duas pernas e melhorar minha performance. Eu espero que eu possa melhorar os 100 metros' disse a adolescente. Disponível em: <http://www.spiegel.de/schulspiegel/leben/paralympics-teilnahmeschuelerin-will-bein-amputieren-lassen-a-995571.html>. Acesso em: 1ํ mar 2015

No Brasil o jornal on-line "Hora de Santa Catarina", veiculado no portal da "Clic-RBS/SC", em matéria difundida em 19 de setembro de 2014 , traz estampados no título e no subtítulo os desejos de Danielle: "Paratleta que teve perna amputada quer retirar a outra perna para melhorar desempenho: Danielle Bradshaw quer vir ao Brasil nas Paralimpíadas de 2016." Disponível em: <http://horadesantacatarina. clicrbs.com.br/sc/esportes/noticia/2014/09/paratleta-que-teve-perna-amputada-quer-tirar-perna-para-melhorar-desempenho-460270/>. 
O uso dos mais variados tipos de tecnologias no esporte não suspende demandas no que tange às relações ontológicas na relação do vivo com o artificial, mas sim as reorganiza, realoca, cria outras/novas formas ontológicas a partir da ontologia tradicional, as quais disputam espaços de legitimidade e força com esta, que permanece, ainda, fortemente presente. Afirmamos isso sustentados em Contreras (2011, p. 139), quando menciona que a hibridação do corpo com a tecnologia "[...] corresponde a toda una ontología e una epistemología, que hunde sus raíces en los câmbios en la representación de los objetos de la natureza y de la tecnologia - los seres vivos y las máquinas".

Assim, não podemos negar que essas novas tecnologias ligadas ao corpo estão causando polêmicas no que diz respeito às fronteiras do humano, confundindo inclusive sua ontologia clássica, afinal, contemporaneamente, o que caracteriza a máquina nos faz pensar aquilo que caracteriza o homem.

O esporte, permeado por corpos cada vez mais hibridizados a aparatos tecnológicos, nos faz pensar algumas questões de cunho ontológico: o que é algo natural? O que é artificial? $\mathrm{O}$ que diferencia natural e artificial? 0 que significa alterar/produzir/destruir algo natural? 0 artificial descaracteriza a natureza do humano? Natural e artificial não são tensões de um mesmo e único processo do devir ontológico? Pode algo artificial se tornar autônomo e mudar seu rumo?

No que tange às questões axiológicas podemos afirmar que uma das características mais perturbadoras entre os cientistas e profissionais que lidam com questões relacionadas à tecnologia neste início de século XXI são os esforços de formular códigos de ética capazes de orientar seus membros frente a uma grande quantidade de dilemas de cunho moral e ético, causados pela fusão do humano com a tecnologia. No desporto, essas discussões vão calhar diretamente na regulamentação do doping e na categorização de provas esportivas:

En concreto, tal posibilidad genera cuestiones éticas y jurídicas ineludibles. En este sentido, la paradoja que se plantea es que los implantes mecánicos nacieron con un evidente objetivo terapéutico y restaurativo de las capacidades físicas de los deportistas (normalmente, discapacitados), pero pueden tener efectos mejoradores del rendimiento físico. El actual desarrollo técnico ha conducido, en algunas ocasiones, a que los deportistas implantados (ciborgs) obtengan mejores marcas y resultados deportivos que los deportistas 'normales', por lo cual no sólo reclaman que no sean limitados a participar en competiciones para discapacitados sino que también exigen competir en las mismas competiciones que los atletas normales (TRIVIÑO, 2012, p.9).

Dessa forma, essas problemáticas levantam questões de cunho axiológico, para se estabelecer valores no âmbito da política e da ética: qual a índole de um produto tecnológico? O homem tem mais valor que a natureza? Até que ponto o homem pode usar a tecnologia para seu próprio benefício? O que configura um doping tecnológico no âmbito esportivo/ paradesportivo? O que é uma trapaça no uso da tecnologia para com o corpo no aumento da performance? Quais os limites que devemos ter com o uso da tecnologia?

Assim, o presente ensaio pretende discutir a problemática do uso da tecnologia no âmbito esportivo e os desdobramentos desta no que tange a debates de cunho ontológico e axiológico. Fizemos isso tomando como fio condutor de reflexão o caso da paratleta britânica Danielle Bradshaw, que teve repercussões internacionais, que ecoaram também no Brasil por ser ele o país-sede da próxima paralimpíada. 


\section{CORPO E TECNOLOGIA: ONTOLOGIA E AXIOLOGIA NO DESPORTO}

Danielle Bradshaw nasceu na Inglaterra no ano de 1999, com o joelho direito deslocado e com displasia de desenvolvimento em ambos os quadris. Tal situação fez com que Danielle se submetesse a mais de 12 cirurgias na tentativa de melhorar sua condição de mobilidade. A britânica passou sua infância sobre cadeiras de rodas, e, aos 11 anos, após inúmeras tentativas frustradas de reabilitação, Bradshaw teve a perna direita amputada. Feita a amputação, Danielle ganhou uma prótese e começou a andar para, em seguida, realizar o sonho de praticar atletismo.

Após esse incidente, ocorrido em setembro de 2010, Danielle começou a correr a prova de 100 metros rasos e pouco tempo depois já estava participando de provas paradesportivas locais e nacionais, ganhando diversas medalhas. Danielle compete na categoria $\mathrm{T}_{42}{ }^{2}$. Devido aos excessivos treinamentos, a perna esquerda da paratleta ficou sobrecarregada, causando deformações dolorosas nos dedos e várias lesões no tendão. Por causa da diminuição de seu ritmo nas provas, ela agora deseja que cirurgiões amputem sua outra perna para que, assim, ela possa correr com mais velocidade ${ }^{3}$.

O caso de Danielle nos remete a pensar que nós só temos um corpo na medida em que nos apropriamos de linguagens, símbolos e imagens. Nosso corpo corresponde antes de tudo a vetores semânticos e sintáticos de diferentes construções e existências que estão fora dele, como o voo dos pássaros reproduzido na asa-delta humana. Dessa forma, podemos nos perguntar: quantos corpos nós, humanos, já tivemos ao longo da história? Quantos embustes, disfarces, fantasias, máscaras, camuflagens técnicas e tecnológicas não criamos para lidar com a natureza e a cultura (LEROI-GOURHAN, 2001, p. 127)? Pela observação histórica da rotação de signos que atravessaram o corpo, podemos afirmar que ele é sempre uma construção. Toda vez que se cria/estabelece um novo entendimento de corpo, cria-se e se estabelece uma nova forma de entendimento de sua estrutura - um novo modelo cognitivo de corpo é fornecido.

Entendemos, pois, a tecnologia como um elemento intensificador do corpo, gerador de um devir, compreendida como uma alteradora no plano da intensidade e não no plano da identidade (BARTOLO, 2007). Nesse sentido, de antemão, queremos deixar bem claro que 0 artefato técnico fundido com o biológico não faz com que o corpo deixe de ser corpo, ou com que o humano deixe de ser humano, mas faz, sim, com que ele intensifique/potencialize esse corpo/humano, fazendo parte dele por um processo de corporização.

A síntese corpo e tecnologia caracteriza o corpo biotecnológico, no qual a tecnologia não se limita a estar à nossa volta, como positivamente se pensava a natureza, ela literalmente nos "incorpora". O filósofo francês Michel Serres compactua com tal entendimento, pois ao versar sobre corpo e tecnologia, anuncia que essa fusão soluciona o velho problema do acordo ou da síntese entre natureza e cultura:

\footnotetext{
2 Utiliza-se essa expressão T42 para identificar a classe referente a cada deficiência. O $T($ track) = pista, ou seja, ela corre em pista,e a numeração 42 é para indicar o grau de comprimento motor do atleta.

3 A insatisfação da paratleta fica visível no trecho da reportagem veiculada pelo jornal on-line Hora de Santa Catarina, publicado no portal da "Clic-RBS/SC" em matéria publicada em 19 de setembro de 2014: "Danielle, que mora em Tameside, na Inglaterra, tem como inspiração Oscar Pistorius, o primeiro atleta olímpico e paralímpico da história a competir de maneira simultânea e em igualdade de possibilidades com atletas não deficientes em nível mundial e olímpico, e sua prótese é do mesmo estilo da usada pelo paratleta. Porém, durante os treinos, a perna 'saudável' de Danielle the causa dor devido a problemas nos tendões e a prejudica, por isso a adolescente não consegue melhorar seu tempo. - 'Um dia ela será atleta paralímpica, mas precisa desse procedimento (a nova amputação) para melhorar os seus tempos' — disse teve-perna-amputada-quer-tirar-perna-para-melhorar-desempenho-460270/>. Acesso em: 1ำ mar. 2015.
} 
Nada mais 'natural' do que o gesto de instalar um equilíbrio distante de uma antiga estabilidade, e isso porque a palavra natureza significa, justamente, um nascimento, e o processo em questão descreve o nascimento da própria vida a partir do inerte preso na armadilha do segundo princípio da termodinâmica; mas a repetição do processo projeta a história, essa mesma história que nos separa da evolução vital, bacteriana, vegetal ou animal. A cultura começa pela natureza; ela é a própria natureza, cuja continuidade se dá por outros meios. Por isso, a cada etapa, ela se torna irreconhecível. Não teríamos jamais nos transformado nos homens que somos sem o treinamento (SERRES, 2003, p. 46).

Em outras palavras, partimos das críticas de Heidegger (2013, p. 7-9) acerca da ontologia tradicional e consideramos que essa última só é capaz de pensar o ser, cujo fundamento principal é a noção clássica de natureza sempre fixa, bloqueando o acesso a problemáticas filosóficas do ser inevitavelmente sujeito e indeterminado às dinâmicas de seu contexto. Nesse sentido, a natureza não pode consistir o fundamento irredutível da temporalidade humana, mas, sim, sua historicidade, do mesmo modo se deve interpelar o corpo.

A noção de que a cultura é um arranjo do tipo artificial, que seus graus de complexidade garantem a construção de enclaves protetores face à hostilidade da natureza enquanto, simultaneamente, são capazes de instrumentalizá-la sem corromper sua quididade, funda-se na expectativa, errônea e precária, de que a cultura é essencialmente contraditória à natureza. Nesse contexto, artificial é concebido como aquilo que resulta da intervenção consciente do homem em um processo que não se realizaria de outro modo (DUTRA, 2011, p. 147).

Outra problemática quando falamos de ontologia é a crença num Deus transcendente que fez o homem e o mundo. Logo, toda "mutação" feita nesse mundo e nesse homem é vista como infração à "lei de Deus", à lei da natureza. Dessa forma, a não ser que se acredite que o que é inviolável no vivo é nomologicamente derivável de sua natureza transcendental, o engenheiramento da vida não seria uma impossibilidade ética condenável (DUTRA, 2011).

Retomando as questões do desporto/paradesporto, Triviño (2012) menciona que são três os tipos de modificações melhoradoras causadas pelo avanço tecnológico, que podem experimentar os desportistas no presente ou num futuro não muito distante. São elas: 1) melhoramento por dopagem genética que pode se caracterizar de duas maneiras: a) por intervenções somáticas; e b) por modificações genéticas em linha germinal; 2) modificações melhoradoras feitas a partir de implantes no corpo que converteriam os atletas em ciborgues; e 3) melhoramentos oriundos da criação de seres híbridos e quimeras.

O caso analisado neste ensaio se encaixa no segundo tipo de modificação, que são os implantes corporais - ciborgue 4 . Os implantes mecânicos nasceram com um objetivo terapêutico e restaurador das deficiências, a fim de oportunizar, por exemplo, que pessoas deficientes se tornassem atletas. Porém, o avanço tecnológico superou a barreira simplesmente restaurativa e potencializou seus produtos para um âmbito que transcende a restauração e ocasiona efeitos que melhoram as capacidades físicas e técnicas de tais atletas. Na verdade, a tecnologia chega a proporcionar efeitos trans-humanos ${ }^{5}$ a esses esportistas na medida em que os potencializa para além do que poderiam fazer em nível "normal de condições".

\footnotetext{
40 termo ciborgue deriva de cyborg, que é a abreviatura de cybernetic organism. Kybernetes vem do grego, que significa "o homem que dirige". 50 termo trans-humano, segundo Santos (CTeMe, 2005) apud Camargo e Vaz (2012), diz respeito a uma narrativa de obsolescência do corpo humano "natural", diante das transformações tecnológicas e econômicas que fazem parte da contemporaneidade. Fazemos o uso desse termo durante todo o texto, e compactuamos com o sentido dele. Porém, é importante destacarmos aqui que, quando fazemos o uso desse termo, o estamos empregando diante do contexto de uma "ontologia tradicional" que permeia o esporte que, nesse sentido, corpos alterados tecnologicamente em um certo nível, segundo o contexto esportivo, não dizem respeito a uma condição humana dita "natural". Assim, não entendemos que de fato essa alteração por meio de tecnologia faz desse ser modificado um "não humano", mas sim que tais transformações fazem parte do próprio devir do humano.
} 
Un efecto terapéutico sería aquel que repara el organismo hasta colocarlo aproximadamente en la situación previa que tenía antes de una enfermedad. Un efecto mejorador sería aquél que daría lugar a un aumento del potencial natural humano dentro del ámbito típico de lo que es un ser humano, como por ejemplo, incrementar el coeficiente intelectual de un individuo de 100 a 104. Un efecto transhumano sería el mejoramiento superhumano, es decir, el aumento de las capacidades de una persona por encima del ámbito característico de la especie humana, como sería por ejemplo aumentar el coeficiente intelectual de un individuo de 100 a 200 (TRIVIÑO, 2012, p. 10).

No caso de Danielle, ela não é apenas uma atleta deficiente que se deu por satisfeita fazendo uso da tecnologia para sanar suas deficiências, melhorando suas capacidades físicas e técnicas, ela quer otimizar ao máximo sua condição, ela clama por um efeito transhumano na medida em que sua perna "natural" se encontra no mesmo nível de uma perna de qualquer atleta normal, ou seja, ela está exposta a lesões e estresses causados pela rotina de treinamentos, assim como todos. O problema para o esporte contemporâneo reside exatamente nesse nível de melhora que (supostamente) transcenderia uma determinada compreensão do humano e sua ontologia, pois a lógica binária na qual o desporto está suspenso não abarca tal situação. Essa ontologia tem no seu âmago a ideia de que esse corpo, ao ser modificado pelo uso das tecnologias, fica descaracterizado de sua condição humana, ou seja, ele passa a ser visto como uma entidade "trans-humana". Afirmamos isso pois acreditamos que 0 principal problema ontológico causado pelas melhoras tecnológicas está no fato de o mundo, o desporto e o humano estarem estruturados numa compreensão sob um nexo binário: sujeito/ objeto, natureza/cultura, atleta/paratleta, natural/artificial, carne/silício, corpo/mente etc. Essa estruturação não dá conta de conceber esses atletas tecnologicamente modificados.

Assim, as relações modernas baseadas em pressupostos dualísticos e organizadas a partir de lógicas binárias entre natureza e cultura, ou ainda, natural e artificial, parecem limitadas para a compreensão, classificação e organização das transformações tecnológicas ocorridas nos corpos dos atletas contemporâneos, pois tais saberes e práticas biotecnológicas vêm confundir as antigas relações existentes entre os pares natureza/cultura ou natural/artificial, como o caso do novo tipo de atleta emergente (MANSKE, 2013, p. 305).

Considerando essa lógica binária, se Bradshaw amputasse a perna natural, ela acabaria por ocupar um "não lugar" dentro do desporto frente aos binários existentes: ela não seria uma atleta normal, nem uma atleta deficiente. Ela seria uma atleta duplamente potencializada, passaria do limite da correção e da amplificação/otimização para uma condição "trans-humana". Dessa forma, atletas implantados estão alcançando marcas superiores a atletas normais, como é o caso do corredor sul-africano Oscar Pistorius. Manske (2013, p. 300) coloca o paratleta Oscar Pistorius no mesmo caso em que agora situamos Danielle:

Embora o atleta tenha acoplado as próteses em seu corpo, tal como num paradigma
bivalente, essas próteses são denominadas de 'inteligentes', pois percebem o
movimento do atleta e se adaptam às exigências desse movimento. Desse modo,
Pistorius não é um atleta deficiente que apenas adotou pernas mecânicas para
sanar suas deficiências, ele tornou suas deficiências em maximização de suas
potencialidades.

Qual a fronteira entre um tratamento terapêutico e um tratamento melhorador? Como estabelecer critérios de demarcação desses dois campos que muito se aproximam? Qual o limite para uma suposta melhora "trans-humana"? Que decisões tomará o desporto ante as 
melhoras "trans-humanas" que podemos visualizar diante dos avanços tecnológicos? Quais os critérios para se distinguir um efeito terapêutico melhorador de um efeito "trans-humano"?

Vejamos o que Triviño descreve sobre os paradoxos tensionados até aqui:

Sin embargo, otro deportista que quisiera reemplazar su brazo o su pierna por uno artificial que le mejorara sus marcas deportivas o que le permitiera jugar mejor, no podría a tenor de la actual legislación deportiva. Pero, ¿cuál es la diferencia ética entre los dos tratamientos? Piénsese en otro ejemplo que podría producir perplejidad si se generalizasen las prohibiciones de dispositivos que mejorasen el rendimiento deportivo ("cualquier dispositivo técnico que incorpore resortes, ruedas o cualquier otro elemento que proporcione a quien lo usa una ventaja sobre otros atletas que no usen tal dispositivo"). Según esta prohibición estaría prohibido que un golfista utilizara lentillas oculares que paliasen una miopía, pero no estaría prohibido que jugara después de haberse sometido a una operación de erradicación de la miopía. Por cierto, éste es el caso de Tiger Woods. Sería muy extraño y paradójico que se le prohibiera jugar si llevara lentillas, pero que se le permitiera si ha sido operado, cuando el resultado a efectos prácticos es el mismo (TRIVIÑO, 2012, p.16).

A World Anti-Doping Agency ${ }^{6}$ (WADA), criada pelo Comitê Olímpico Internacional (COI) em 1999, nasce com o objetivo de lutar contra o doping. Solanes e Valero (2014, p. 56) apresentam a definição de doping difundida por essa agência:

[...] el avance cientíico y médico en pos de mejorar el rendimiento físico de los seres humanos, y de los deportistas en particular, que ha ido explorando nuevas vías hasta llegar al actual dopaje genético, entendido como la introducción y consiguiente expresión de un transgen o la modulación de la actividad de un gen existente para lograr una ventaja fisiológica adicional (SOLANES; VALERO, 2014 p. 54).

Desse modo, segundo Solanes e Valero (2014, p. 56), poderíamos destacar três valores fundamentais que fazem o $\mathrm{COI}$ considerar o doping prejudicial à saúde dos atletas, e antagônico à ética esportiva, "[...] estos valores serían: la protección de la salud de los deportistas, el juego limpio entendido como equitativo y carente de engaño y la integridad y unidad del deporte conforme a sus bienes internos a la práctica deportiva".

Diante disso, podemos detectar que o uso da tecnologia - e, por consequência, do doping - no desporto/paradesporto traz implicações sobre três problemáticas: o próprio uso de tecnologia no esporte, a saúde do atleta e a ética esportiva. Consideramos, pois, que tais problemáticas sofrem de ambiguidades que não são devidamente compreendidas conforme uma "ética universalista", que determina certo/errado, natural/artificial no que tange à hibridização do corpo com a tecnologia no âmbito do esporte. Denunciamos isso na medida em que questionar o uso do doping a partir de argumentos acerca da saúde, da tecnologização do esporte e da ética (fair-play) esportiva é contraditório, vista a própria lógica maquínica do esporte - como já nos relatou $\mathrm{Vaz}^{8}$. Desse modo, a relação do uso de tecnologias no esporte, como já destacamos, enfrenta problemas muito mais profundos do que os problemas de normatividade, pois o que está em jogo é uma ontologia do humano e seus limites.

\footnotetext{
6 "Agência Mundial Antidoping".

70 que estamos chamando aqui de "ética universalista" corresponde a códigos de valores que não consideram o humano em seu devir (movimento de mudanças) buscando o enquadramento deste em categorias estabelecidas a priori, buscando, assim, suprimir suas particularidades e diferenças. Tal ética universalista estaria baseada naquilo que Heidegger (2013) nos mostra acerca de uma ontologia clássica, a qual pressupõe o humano com uma natureza sempre fixa.

8 VAZ, A. F. Do culto à performance: esporte, corpo e rendimento. Trabalho apresentado no XI Congresso Brasileiro de Ciências do Esporte, Florianópolis, set. 1999.
} 
Assim, é importante aqui destacar que a relação do corpo com o esporte não evidencia apenas o uso de tecnologias por meio deste, mais que isso, evidencia um olhar sobre o próprio corpo como máquina, porque "[...] todo esse maquinário só faz sentido se o próprio corpo for observado como máquina. $O$ instrumento já não é um prolongamento do corpo, nem mesmo um apêndice da máquina. Corpo e máquina confundem-se, assemelham-se, igualam-se [...]"'. O corpo então não incorporaria apenas o arsenal de tecnologias presentes no esporte, mais do que isso, ele incorporaria uma semiótica do esporte, uma incorporação mimética.

O esporte e sua exigência para o aumento ou manutenção do alto rendimento pressupõem uma redução maquínica do corpo ao considerá-lo como um ente manipulável, e é esta a premissa presente na teoria do treinamento, que inclusive é reconhecida pelos atletas "[...] na medida em que criam e empregam expressões como 'treinar é entregar o corpo' ou 'a dor faz parte do meu uniforme', 'não me lembro o último dia em que acordei sem algum tipo de dor"' (VAZ, 2005, p. 30). A incorporação mimética da semiótica do esporte estaria mais representada ainda quando os limites do esporte transcendem a arena esportiva e passam a constituir fronteiras a serem vencidas não apenas no jogo esportivo, mas também pela própria humanidade, em que: "os resultados esportivos encarnam a realização particular de uma universalidade da espécie humana sintetizada na figura individual do recordista, portador do rendimento máximo" (VAZ, 2005, p. 31).

Sob esse aspecto, a própria noção de corpo e ser humano no esporte, ou uma ontologia do humano no esporte, seria pautada num corpo como máquina, um conjunto de peças que deve funcionar em seu máximo rendimento e, nesse sentido, a própria utilização de tecnologias para a manutenção/aumento dessa performance se torna imprescindível. Diante disso, cabem alguns questionamentos: até que ponto, em que medida, ou quais os parâmetros para 0 estabelecimento de valores e dilemas de cunho ético que norteiam o uso destas tecnologias no esporte? Até que ponto seria contraditória a proibição dos usos de certas tecnologias para 0 aumento da performance, visto o caráter maquínico que permeia toda a lógica esportiva?

O esporte, ao mesmo tempo em que exige a máxima performance e o seu aumento constante - pautado na quebra dos limites "naturais" do corpo humano -, opera paradoxalmente com uma ontologia tradicional de ser humano que freia seu próprio adágio . Isso implica afirmar que o esporte na modernidade é atravessado por uma tentativa de ética universalista que parece estar muito distante das características tecnológicas que fundam a constituição desses atletas.

Com base nessa ontologia tradicional que pauta questões axiológicas no desporto, a hibridização do atleta/corpo com a tecnologia fica relegada à imposição de uma ordem classificatória que divide esses atletas em dois grupos: corpos legitimamente humanos conformes o código axiológico da prática desportiva; e corpos trans-humanos que fogem de uma axiologia universalista desportiva.

Nesse sentido, parece que o esporte está diante de sérios litígios ao tentar resolver tais problemas a partir destas ordenações/classificações presas à ontologia tradicional, pois, segundo Bauman (1999), a ambivalência (representada aqui pelas problemáticas que emergem do corpo de Danielle e de outros atletas/corpos híbridos) é resultado da tentativa de classificação e, por consequência, exige-se um maior esforço no ato de classificar. Então, uma 
possível saída seria a insistência na tentativa mais exata e mais precisa da classificação? A respeito disso, Bauman (1999, p.11) destaca que:

[...] Embora nascida do impulso de nomear/classificar, a ambivalência só pode ser combatida com uma nomeação ainda mais exata e classes definidas de modo mais preciso ainda: isto é, com operações tais que farão demandas ainda mais exigentes (contrafactuais) à descontinuidade e transparência do mundo e assim darão ainda mais lugar à ambiguidade [...].

Dessa forma, talvez não haja saídas além de pensar tais corpos a partir de suas próprias ambivalências. Considerar isso seria abrir possibilidades para pensar os atletas contemporâneos hibridizados com a tecnologia, atletas que transcendem o binário "normal X deficiente", "humano X trans-humano", já que a tecnologia está abrindo fossos dentro dessas duas categorizações na medida em que um atleta deficiente/normal está sujeito a melhoramentos tecnológicos que o diferenciam do normal e do deficiente dentro de suas próprias categorias.

Partir de suas ambivalências seria uma opção interessante, uma vez que nos traz a possibilidade de considerar o corpo - e por consequência, o humano - como uma rede de múltiplas variações e evoluções, assumindo que o corpo é sempre muito mais do que a ciência determina que ele seja - indo contra uma ontologia clássica e uma ética universalista. "A identidade é definida de forma relacional, puramente como uma função das diferenças no interior do sistema. A relação entre significado e significante é inteiramente arbitrária" (PETERS,2000, p.20). Com isso:

\begin{abstract}
O nascimento e a morte dos corpos, ou das mentes conscientes, não conseguem delimitar um puro espaço de uma vida humana. Ambos são processos que envolvem continuidade genética, continuidades de ideias e de linguagem, de sociedades e de mundos. Isso não significa que não haja algo como a vida humana, ou que ela não seja valiosa. Significa que a vida humana não é um absoluto e que as bordas não são a maior certeza sobre a qual se poderiam construir sistemas de verdades (WILLIAMS, 2012, p.42).
\end{abstract}

Isso implicaria repensar tanto as questões axiológicas e a dimensão ontológica do humano no esporte, facetas que estão ligadas, principalmente, à problematização da hibridização do corpo frente à tecnologia no âmbito esportivo. A axiologia esportiva, em vez de considerar o humano preso a uma ontologia clássica, que nega suas singularidades por meio de um fundamento central, deveria estar pautada numa ontologia que considera o devir humano não a partir de um modelo de corpo pronto e concluído, uma vez que ele é resultado de construções e desconstruções diante de sua historicidade.

Isso não quer dizer que tudo vale. Visto que, por consequência, pensar o humano a partir de uma ontologia que considere seu devir implica também pensar uma ética cujo critério seja exatamente o humano a partir de seu devir histórico - de sua historicidade. Isso implica dizer que os pressupostos que fundamentam a definição de humano/corpo no esporte, o limite frente ao uso de tecnologias - e outras questões inerentes a tal problemática - não se fundamentariam mais numa ontologia clássica. Assim, a referência e os pressupostos que definiriam questões axiológicas no desporto não estariam já dados a priori, como um ponto arquimediano, mas, sim, estariam amparados na discussão desses pressupostos em processos de movimentos incessantes.

Sob essa lógica, não haveria um lugar posto ou um conceito já dado de humano/corpo nem de ética esportiva, mas, sim, o constante questionamento acerca de ambos. Assim sendo, 
0 debate acerca dos pressupostos que fundamentam o esporte e o uso de tecnologias neste considerariam a historicidade do próprio esporte e do próprio ser humano como corpo. Ambos estariam em consonância com o eterno devir. Os pontos de referência ontológico e axiológico deixariam de ser fixos, eles não seriam dados a priori, ao contrário, seriam construídos e reconstruídos constantemente a partir do próprio e constante movimento de mudanças inerentes tanto ao esporte quanto ao ser humano e seus limites, ou seja, as referências seriam o esporte e o ser humano em seu devir.

\section{CONSIDERAÇÕES FINAIS}

Retomando o objetivo de nosso ensaio, que foi discutir a problemática do uso da tecnologia no âmbito esportivo e os desdobramentos desta no que tange a debates de cunho ontológico e axiológico, tendo como pano de fundo o caso da paratleta britânica Danielle Bradshaw, entendemos que corpo é um enigma que nos oferece pistas, indícios, signos, sintomas que desconstroem todo tipo de taxonomia e, portanto, o contexto cultural que 0 sustenta. Nessa desconstrução taxionômica, o exercício de desconstruir não deve ser visto como sinônimo de censura ou aniquilamento, pelo contrário, trata-se de se libertar de amarras epistêmicas e metafísicas para que os sentidos de corpo não fiquem presos a uma matriz antecipatória que não deixe emergir outros significados. É um desafio para emancipar o corpo de ontologias que o condenam a matrizes de ordenação.

Diante dessa tentativa de ordenação no contexto esportivo no que tange ao uso de tecnologias, vimos que corpos como o de Danielle Bradshaw, Oscar Pistorius e tantos outros geram "ambivalência" (BAUMAN, 1999) no sistema esportivo, uma vez que não é possível ter certeza da permissão ou não do uso dos aparatos técnicos/tecnológicos; se é possível ou não caracterizar esses corpos dentro de uma ética esportiva,valendo-se dos argumentos (por nós acusados como contraditórios) da lógica desta.

Os regulamentos éticos que regem o esporte, pautados teórica e metodologicamente numa ontologia tradicional, buscaram organizar a realidade formada pelas relações entre os atletas/viventes segundo seus respectivos sistemas categoriais, cujas bases estão fixadas na epistemologia e na metafísica ocidentais. Dessa forma, o corpo atravessado pela tecnologia no âmbito esportivo precisa ser visto sob o viés epistemológico de outras compreensões de ontologia e axiologia para além daquelas que até agora o enxergaram. É nesse ponto que a consideração da ambivalência desses corpos oferece novas (re)interpretações e compreensões para se (re) pensar novas formas de ontologia e axiologia no esporte, nos quais os modelos de uma ética esportiva devem se transformar em função dos devires apresentados pelos atletas/viventes.

\section{REFERÊNCIAS}

BÁRTOLO, José. Corpo e sentido: estudos intersemióticos. Covilhã: Livros LabCom, 2007.

BAUMAN, Zygmunt. Modernidade e ambivalência. Rio de Janeiro: Zahar, 1999.

CAMARGO, Wagner Xavier; VAZ, Alexandre Fernandez. De humano e pós-humano - Ponderações sobre o corpo queer na arena esportiva. In: COUTO, Edvaldo Souza; GOELLNER, Silvana Vilodre. 0 triunfo do corpo: polêmicas contemporâneas. Petrópolis: Vozes, 2012. p. 119-144. 
CONTRERAS, Raúl Cuadros. Ontología y epistemologia cyborg: representaciones emergentes del vínculo orgânico entre el hombre y la naturaleza. Revista Iberoamericana de Ciencia, Tecnología y Sociedad, Buenos Aires, v. 7, n. 19, p. 131-141, dic. 2011.

DUTRA, Roger Andrade. As teorias do ciborgue: o maquínico e o humano em Stanislaw Lem e Donna Haraway. Revista Ibero Americana de Ciência, Tecnologia y Sociedade, Buenos Aires, v. 19, n. 7 , p. 143-156, dic. 2011.

HEIDEGGER, Martin. Ontologia: hermenêutica da facticidade. Tradução de Renato Kirchner. 2. ed. Petrópolis: Vozes, 2013. (Coleção Textos Filosóficos).

LEROI-GOURHAN, André. Os caçadores da pré-história. Tradução de Joaquim João Coelho da Rosa. Lisboa: Edições 70, 2001. (Perspectivas do homem).

MANSKE, George Saliba. Atletas do século XXI: ou das fusões biotecnológicas nos atletas de alto rendimento. Movimento, Porto Alegre, v. 19, n. 1, p. 289-308, jan./mar. 2013.

PETERS, Michael. Pós-estruturalismo e filosofia da diferença: uma introdução. Tradução de Tomaz Tadeu da Silva. Belo Horizonte: Autêntica, 2000.

SERRES, Michel. Hominescências: o começo de uma outra humanidade? Tradução de Edgard de Assis Carvalho e Mariza Perassi Bosco. Rio de Janeiro: Bertrand Brasil, 2003.

SILVA, Tomaz Tadeu. Nós, ciborgues: o corpo elétrico e a dissolução do humano. In: HARAWAY, Donna; KUNZRU, Hari; SILVA, Tomaz Tadeu. (Org.). Antropologia do ciborgue: as vertigens do pós-humano. Belo Horizonte: Autêntica, 2009. p. 7-15.

SOLANES, Raúl Francisco Sebastián; VALEROS, Víctor Páramo. Ética del deporte y dopagem: el caso Armstrong. Fair Play: Revista de Filosofía, Ética y Derecho del Deporte, Barcelona, v. 2, n. 1, p. 51-71, 2014.

TRIVIÑO, José Luis Pérez. Deportistas tecnológiamente modificados y los desafios al deporte.

Revista de Bioética e Derecho, Barcelona, n. 24, p. 3-19, ene. 2012.

VAZ, Alexandre Fernandez. Doping, esporte e performance: notas sobre os limites do corpo. Revista Brasileira de Ciências do Esporte, Campinas, v. 17, n. 1, p. 26-36, set. 2005.

WILLIAMS, James. Pós-estruturalismo. Tradução de Caio Liudvig. Petrópolis: Vozes, 2012. 
